\title{
REVIEW OF PROPOSED FORMATS FOR SAFETY ANALYSIS REPORTS FOR RADIOACTIVE WASTE REPOSITORIES IN DEEP GEOLOGIC FORMATIONS
}

This report was prepared by Envirosphere Company, EBASCO Services, Incorporated under subcontract $62 \mathrm{Y}-45706 \mathrm{~V}$ with Union Carbide Corporation, Nuclear Division, under contract number WV-1405-Eng-26 with the Energy Research and Development Administration. The subcontract was administered by the Office of Waste Isolation.

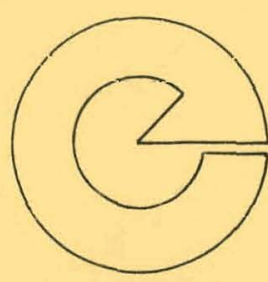




\section{DISCLAIMER}

This report was prepared as an account of work sponsored by an agency of the United States Government. Neither the United States Government nor any agency Thereof, nor any of their employees, makes any warranty, express or implied, or assumes any legal liability or responsibility for the accuracy, completeness, or usefulness of any information, apparatus, product, or process disclosed, or represents that its use would not infringe privately owned rights. Reference herein to any specific commercial product, process, or service by trade name, trademark, manufacturer, or otherwise does not necessarily constitute or imply its endorsement, recommendation, or favoring by the United States Government or any agency thereof. The views and opinions of authors expressed herein do not necessarily state or reflect those of the United States Government or any agency thereof. 


\section{DISCLAIMER}

Portions of this document may be illegible in electronic image products. Images are produced from the best available original document. 


\section{REVIEW OF PROPOSED FORMATS FOR SAFETY ANALYSIS REPORTS FOR RADIOACTIVE WASTE REPOSITORIES IN DEEP GFOLOGIC FORMATIONS}

SEPTEMBER 1977

Prepared By

Envirosphere Company Ebasco Services Incorporated 19 Rector Street New York, New York 10006
This report prepared as an account of work This repon was prepared as anemment. Neither the sponsored by the United United States Department of United Stes nes thely employees, nor any of their Energ. nor any of thets er their employees, makes contracton, subceress or implied, or assumes any logal any warranty, express or in for the accuracy, completeness liability or responabion in for the aparatus, product or or usefulness of any information that its use would no process ditclosed, or represe the

\section{NOTICE}

This report was prepared as an account of work sponsored by the United States Government. Neither the United States nor the Energy Research and Development Administration, nor any of their employees, makes any warranty, express or implied, or assumes any legal liability or responsibility for the accuracy, completeness or lisefulness of any information, apparatus, product or process disclosed, or represents that its use would not infringe privately owned rights. 
REVIEW OF PROPOSED FORMATS FOR SAFETY

ANALYSIS REPORTS FOR RADIOACTIVE WASTE

REPOSTTORIES IN DEEP GEOLOGIC FORMATIONS

\section{TABLE OF CONTENTS}

$\underline{\text { Page }}$

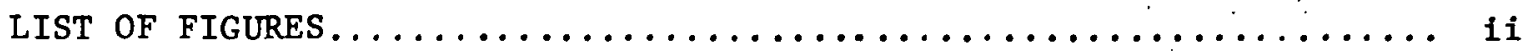

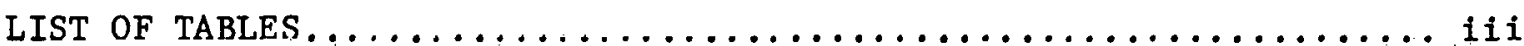

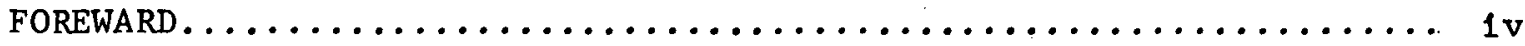

I. BACKGROUND................................... 1

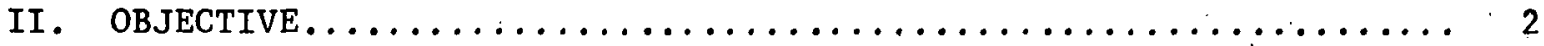

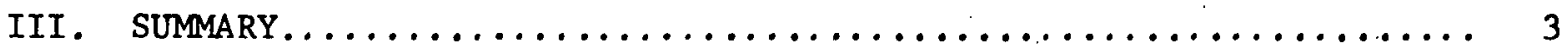

IV. REVIEW OF PROPOSED SAR OUTLINES .................. 4

A. Format and Content Overview.................... 4

B. Detalled SAR Outline Review Comments............... 7

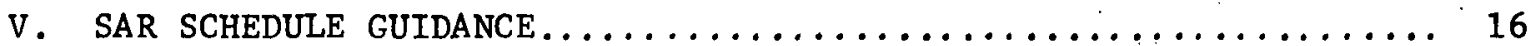

VI. SUGGESTIONS FOR ADDITIONAL SAR SUPPORT EFFORTS ........... 24 


\section{LIST OF FIGURES}

Page

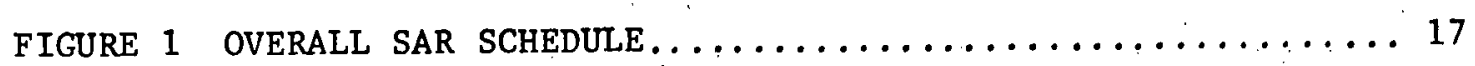

FIGURE 2 PSAR DEVELOPMENT SCHEDULE................... 19

FIGURE 3 SAR CHAPTER PREPARATION SEQUENCE LOGIC............. 20 


\section{LIST OF TABLES}

Page

TABLE 1 FORMAT AND CONTENT OVERVIEW SUMMARY.............. 6

TABLE 2 RECOMMENDED OUTLINE FOR SAR CHAPTER $5 \ldots \ldots \ldots \ldots \ldots \ldots \ldots$

TABLE 3 RECOMMENDED OUTLINE FOR SAR CHAPTER $6 \ldots \ldots \ldots \ldots \ldots \ldots \ldots$

TABLE 4 TENTATIVE LICENSING SCHEDULE INPUT............. 18 
FOREWORD

This report was prepared under a subcontract with Union Carbide Corporation, Nuclear Division, a United States Energy Research and Development Administration (ERDA) contractor. This subcontract was administered by the office of Waste Isolation (OWI), program manager for the National Waste Terminal Storage (NWTS) Program. The principal objective of the NWTS Program is to provide facilities in various deep geologic formations at multiple locations in the United States that will safely dispose of the radioactive waste generated by commercial operations and that must be delivered to a federal repository for terminal storage. These federal repositories will be 1 icensed by the Nuclear Regulatory Commission (NRC).

The NRC generally requires that a safety analysis report be prepared by the applicant for a license for a major facility that is a part of the nuclear fuel cycle. ERDA also requires safety analysis reports (SARs) to be prepared for all new nuclear facilities constructed under its programs. Neither ERDA nor NRC has developed guidelines for the contents of SARs for federal waste repositories. Therefore, OWI has initiated this project to review existing format guidelines in 1 ight of established nuclear licensing experience and knowledge of current NRC regulations, to suggest contents for an SAR, and to provide a schedule for the development of an SAR for a federal repository. This report presents the independent suggestions of the subcontractor, Envirosphere Company, retained for that purpose. The assumptions, views, and conclusions expressed in this document are those of the authors and are not to be interpreted as those of Union Carbide Corporation, Nuclear Division, or of ERDA. 


\section{BACKGROUND}

At present, federal regulations and requirements for the licensing or approval of a waste repository facility do not exist. It is anticipated that in the future, Part 60 of Title 10 of the Code of Federal Regulations (10CFR60) will be developed and will contain requirements for a waste repository comparable to those of 10CFR50 for nuclear power plants, including General Design Criteria, (10CFR50, Appendix A).

It is prudent to assume that, prior to the construction of a waste repository facility, the ERDA will be required to submit an SAR to the Nuclear Regulatory Commission (NRC). As with SAR's for other nuclear facilities, this report must detail the characteristics of the proposed facility and of the proposed site area, and describe the potential for safety-related interactions between the facility and site. Since the NRC has not yet issued a format guide for the preparation of such a report, OWI has proceeded independently with the development of an outline which will serve as the basis for the ERDA design and facility licensing activities.

The NRC's licensing procedures for nuclear power plants and other production and utilization facilities associated with the nuclear fuel cycle generally require that a Preliminary Safety Analysis Report (PSAR) be submitted to NRC by the applicant for a construction permit and that a Final Safety Analysis Report (FSAR) be submitted by the applicant for an operating 1 icense. This PSAR-FSAR terminology has been retained throughout this report.

Under separate subcontracts the Stanford Research Institute (SRI) and Battelle Memorial Institute (BMI) have prepared draft outlines for a waste repository facllity SAR. These two proposed SAR format outlines form the initial basis for this study. 


\section{OBJECTIVE}

The overall objective of this study was to provide licensing engineering guidance to the Office of Waste Isolation towards the development of a waste repository facility. Specifically, the objectives of our study were to:

1. Review and develop comments on two proposed SAR format outlines in light of past nuclear licensing experience and current U.S. Nuclear Regulatory Commission Regulatory Guides. The documents reviewed were "Proposed Outline of Safety Analysis Report for Facilities for Geologic Isolation of Radioactive Wastes," Y/OWI/SUB-77/22320, June 1977 , by Stanford Research Institute, and "Proposed Outline for a Safety Analysis Report for $\dddot{a}$ Radioactive Waste Repository, "Y/OWI/SUB$76 / 7253 / 1$, May 1977 by Battelle Memorial Institute, Columbus Laboratories Division.

2. Provide a schedule containing guidance on the preparation, review and submittal of $\mathrm{SAR}^{\prime}$ ' for a waste repository facility.

3. Identify any studies or development items together with recommended timing and justifications of their need, should it become apparent during the development of tasks (1) and (2) above, that additional information would be necessary for the timely licensing of a waste repository facility. 


\section{SUMMARY}

The following observations summarize the major results of this study:

A. SAR Format Out1ine

1. An SAR format and content guide which satisfactorily addresses the safety concerns requisite to a waste repository facility can be developed within the fundamental framework of Regulatory Guide 3.26 by the incorporation of the salient features of both the BMI and SRI proposed outlines as partially indicated in Section IV of this report.

2. The chapters requiring the most substantia1 further revision and/or development are Chapter 3 "Site Characteristics," Chapter 5 "Facility Description," and Chapter 6 "Process Systems." Additional development would consist of completing the fine structure of the format and Incorporating consistent content descriptions and cross-references within the format framework.

B. SAR Schedule

1. Close coordination of the parallel activities contained in the proposed SAR development schedule will be required to achieve the scheduled goa 1s.

C. Additiona1 SAR Support Efforts

1. The two recommended SAR support efforts are to:

a) Further develop accident scenarios to provide the basis of Chapter 9, "Accident Safety Analysis."

b) Review all NRC Regulatory Guides for applicability to a waste repository facility. 
The review of the two (2) proposed SAR Format Guides, "Proposed Out1ine of Safety Analysis Report for Facilities for Geologic Isolation of Radioactive Wastes," Y/OWI/SUB-77/22320, June 1977, by Stanford Research Institute, (SRI outline) and "Proposed Outline for a Safety" Analysis Report for a Radioactive Waste Repository," Y/OWI/SUB-76/7253/1, May 1977, by Battelle Memorial Institute, Columbus Laboratories Division (BMI outline), was conducted in two phases. First, the general format and content of the SRI and BMI Outlines were reviewed against current NRC SAR Format Guides from Division 1, Power Reactors, and Division 3, Fuels and Materials Facilities, to gain an overview of the degree of conformity with existing formats and the extent of compliance in addressing the informational concerns of the Commission. The second phase consisted of a detailed review of both format and content considering the unique functional characteristics of a waste repository facility.

\section{A. Format and Content Overview}

A fundamenta 1 assumption on which this review is based is that NRC regulatory requirements, similar to those presented in 10CFR50.34, 10CFR50.35 and 10CFR70, will be developed and incorporated into 10CFR60. From these regulations the NRC will then generate Regulatory Guides expressing their interpretation of the requirements necessary to comply with the established regulations. However, until such time that the NRC has completed 10CFR60 for publication and use, guidance must be obtained from judicious, selected reference to existing regulations and regulatory guides.

The NRC Regulatory Guides utilized in this review were:

1. 1.70 Rev 2, "Standard Format and Content of Safety Analysis Reports for Nuclear Power Plants," September 1975

2. 3.25 "Standard Format and Content of Safety Analysis Reports for Uranium Enrichment Facilities," December 1974

3. 3.26 "Standard Format and Content of Safety Analysis Reports for Fuel Reprocessing Plants," February 1975

4. 3.39 "Standard Format and Content of License Application for Plutonium Processing and Fuel Fabrication Plants," January 1976.

It should be noted that Regulatory Guides 3.3 "Gulde to the Contents of Application for Uranium Milling Licenses" February 1973; 3.15 "Standard Format and Content of License Applications for Storage Only of Unirradiated Reactor Fuel and Associated Radioactive Material" October 1973; and 3.24 "Guidance on the License Application, Siting, Design, and Plant Protection for an Independent Spent Fuel Storage Installation" December 1974, were considered but not included in the format and content comparison because their structure and content were not developed to the corresponding level of detail; however, additional insight into the safety concerns of NRC was obtained by evaluating these guides as well. 
of the four guides used in the comparison, Regulatory Guide 3.26 was chosen as the reference format because: a) it was utilized by both SRI and BMI In their outline guide preparation effort and, therefore, should aid in developing consistent review comments; b) it represents current NRC guidance (even though Regulatory Guide 3.39, the most recent Division 3 format guide, was issued almost a year later than Regulatory Guide 3.26, the content only differs in Chapter 6 where the process systems are described) and c) our investigations indicate that all major safety concerns for a waste repository facility will most likely fit within the format structure of Regulatory Guide 3.26. The selection of Regulatory Guide 3.26 as the reference format does not imply that equally attractive alternate approaches could not be employed. At the present stage of waste repository facility development a rigid SAR format outline should not be expected; changes should be anticipated and allowance made for incorporation of these changes into the SAR development plans.

The format and content overview comparison has been summarized and is presented in Table 1. This summary indicates the level of agreement of both the format and descriptive content of the BMI and SRI proposed waste repository outlines with Regulatory Guide 3.26, Fuel Reprocessing Plants, SAR Format Guide. Additionally, SAR Format Guides 3.25 - Uranium Enrichment Facilities, 3.39 Plutonium and Fuel Fabrication Plants, and 1.70, Rev 2 - Nuclear Power Plants are compared on a chapter by chapter basis with Regulatory Guide 3.26 in Table 1. Regulatory Guide 3.25, while containing less definitive content guidance than either Regulatory Guides 3.26 or 3.39, was included to demonstrate the precedence for including "Utility and Support Systems" in Chapter 5 "Facility Design" rather than in Chapter 6 "Process Systems."

The comparative terms used in the summary, in decreasing order of similarity are:
SAME
- generally indicates good agreement with both format and content except for some minor differences. depth of content descriptions and process terminology differences are apparent.
SIMILAR - less agreement, some format rearrangement and omissions,
COMPARABLE - represents a likeness of content considering the differences in system design and function; considerable format modification.

From the review summary, it can be seen that there is a high degree of consistency between NRC Regulatory Guides 3.26 and 3.39. It is also interesting to note that all chapters of the Nuclear Power Plant SAR Format Guide, Regulatory Guide 1.70 Rev 2, find to some extent a comparable chapter in the formats for Fuels and Materials Facilities. This gives some confidence that major safety concerns have been addressed, at least to the extent that these facilities encompass similar hazards.

Except for Chapters 5, "Facility Design," and 6, "Process Systems," the BMI outline is in good agreement with the format and content of the latest Division 3 Regulatory Guides. As expected we found the BMI outline to be overly specific 
TABLE 1

FORMAT \& CONTENT OVERVIEW SUMMARY

A. comparison of the proposed waste respository outlines, NRC SAR format guides $1.70,3.25$ and 3.39 against 3.26 .

U S NRC REGULATORY GUIDES

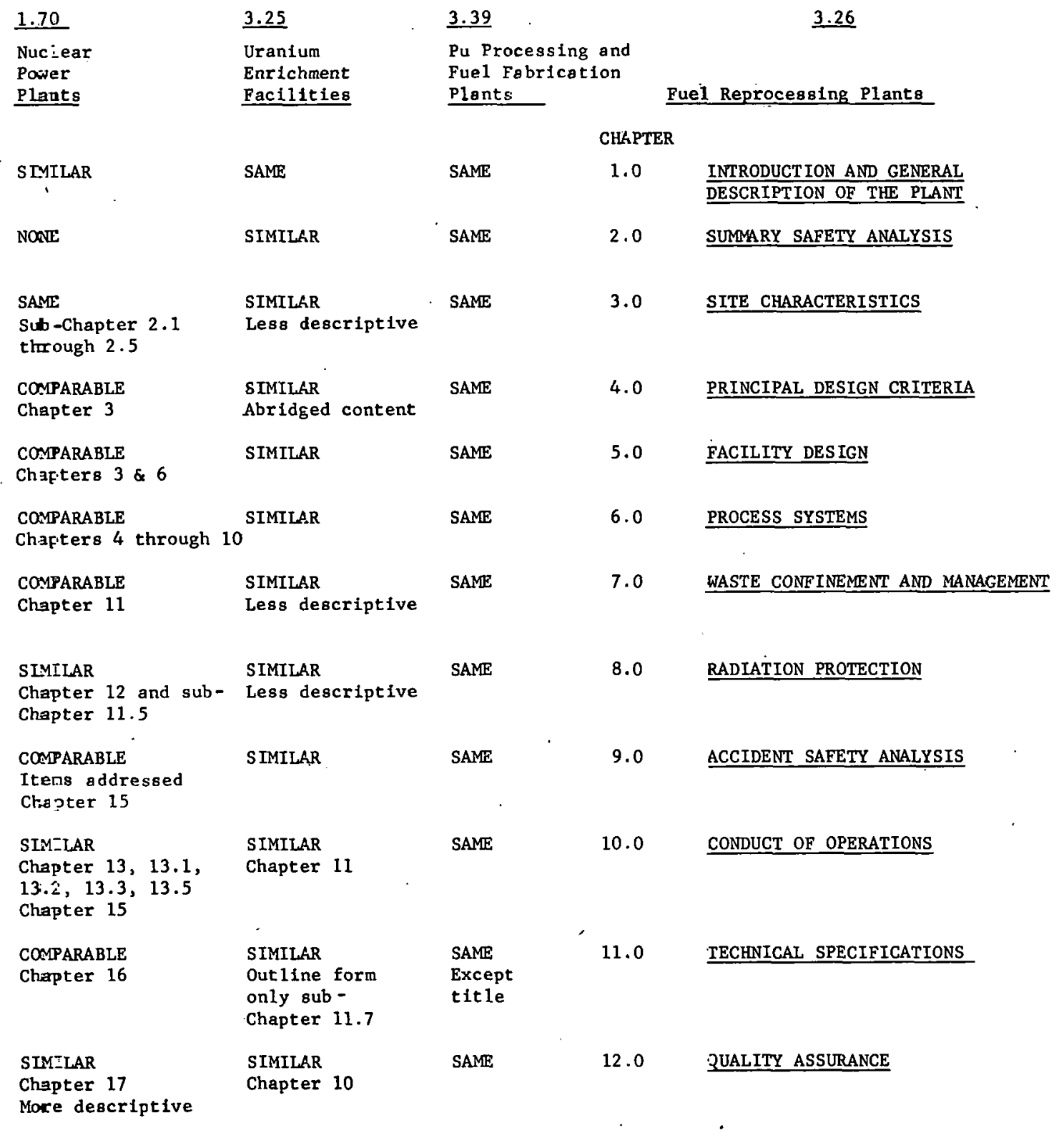

\begin{tabular}{|c|c|}
\hline \multicolumn{2}{|c|}{ Outlines } \\
\hline BMI & $\underline{\text { SRI }}$ \\
\hline $\begin{array}{l}\text { SAME } \\
\text { Abridged Content }\end{array}$ & $\begin{array}{l}\text { SAME } \\
\text { ref to } 3.26\end{array}$ \\
\hline $\begin{array}{l}\text { SIMILAR } \\
\text { Abridged Content }\end{array}$ & $\begin{array}{l}\text { SAME } \\
\text { ref to } 3.26\end{array}$ \\
\hline $\begin{array}{l}\text { SAME } \\
\text { Outline only }\end{array}$ & $\begin{array}{l}\text { SAME } \\
\text { Out of numbering } \\
\text { sequence }\end{array}$ \\
\hline $\begin{array}{l}\text { SIMILAR } \\
\text { Expanded format }\end{array}$ & $\begin{array}{l}\text { SIMILAR } \\
\text { Expanded format }\end{array}$ \\
\hline $\begin{array}{l}\text { See detailed } \\
\text { comments }\end{array}$ & $\begin{array}{l}\text { See detailed } \\
\text { comments }\end{array}$ \\
\hline $\begin{array}{l}\text { See detailed } \\
\text { comments }\end{array}$ & $\begin{array}{l}\text { See detailed } \\
\text { comments }\end{array}$ \\
\hline $\begin{array}{l}\text { SAME } \\
\text { Content rearranged }\end{array}$ & $\begin{array}{l}\text { SAME } \\
\text { Sub-Chapter } 7.1 \text {, } \\
7.1 .1 \text { to } 7.1 .9\end{array}$ \\
\hline $\begin{array}{l}\text { SAME } \\
\text { Expanded format }\end{array}$ & $\begin{array}{l}\text { SAME } \\
\text { Sub-Chapter } 7.2\end{array}$ \\
\hline SIMILAR & $\begin{array}{l}\text { SIMILAR } \\
\text { Expanded form } \\
\text { Chapter } 7.3 \& 8\end{array}$ \\
\hline SAME & $\begin{array}{l}\text { SAME } \\
\text { Chapter } 9\end{array}$ \\
\hline $\begin{array}{l}\text { SAME } \\
\text { Outline only }\end{array}$ & $\begin{array}{l}\text { SAME } \\
\text { Chapter } 10\end{array}$ \\
\hline $\begin{array}{l}\text { SAME } \\
\text { Outline only }\end{array}$ & $\begin{array}{l}\text { SAME } \\
\text { Chapter } 11\end{array}$ \\
\hline
\end{tabular}


in Chapters 5 and 6 being based upon a previous conceptual design study for a facility in bedded salt. Retention of such a format could obviously lead to SAR preparation difficulties as detailed design progresses.

The SRI outline shows a lesser degree of conformity with Regulatory Guide 3.26 format and content. The SRI outline combines "Radiation Protection," "Accident Safety Analysis," and "Waste Confinement and Management" in Chapter 7 and addresses "Long-Term Waste Isolation" concerns in Chapter 8. Although such a structure could be adopted and does have obvious advantages given the unique requirements for long-term isolation in the present case, we believe that a simflar effect can be achieved without large modifications of the reference format by modifying the fine structure of the reference format, particularly in Chapters $3,5,6$, and 9 .

Additional guidance as to the NRC review process can be obtained by investigation of the NRC "Standard Review Plan" (SRP) for Nuclear Power Plants. The Standard Review Plans are tabulated in the identical format as Regulatory Guide 1.70, Rev 2, and contain references to applicable regulatory guides, industrial standards, NRC branch technical positions and pertinent regulations. Thus, Table 1 can also be used to correlate the waste repository facility SAR chapters to NRC positions by utilizing Regulatory Guide 1.70, Rev 2 as an index to the SRP's.

\section{B. Detailed SAR Outline Review Comments}

The chapter by chapter review comments provided below are addressed to the BMI outline. The comments are based on the conceptual waste repository facility description developed by Parsons, Brinckerhoff, Quade, and Douglas, Inc. (Waste Isolation Facility Description, Bedded Sa1t Y/OWI/SUB-76/16506, September 1976) and prior nuclear licensing experience. In addition, our comments were directed toward making the SAR more general in appropriate sections so that it would apply to different geologic sites and different waste handling concepts. Reference has been made to the SRI outline and existing NRC SAR format guides where their content descriptions provide more appropriate guidance for the topic being addressed.

As a general rule, prior nuclear power plant licensing experience indicates that timely NRC revlews are more expeditiously processed when a format which is familiar to the NRC reviewers is utilized and the content is faithfully addressed within the given format. One of the key objectives of a good format and content guide is to require specific information necessary for the evaluation of all safety concerns while allowing enough flexibility to incorporate innovative engineering design modifications during the course of the SAR preparation.

Accordingly the following general guidance has been employed in developing the se comments:

1. Utilize a format that assists the reviewer in "walking through the facility."

2. Reduce repetition by the judicious grouping of topics. This is a document preparation time saver and also reduces the probability of overlooking affected sections when document changes are made during the amendment process. 
3. Maintain the major subchopter headings (topics) general enough so that changes and modifications in plant concept made during the course of design development do not necessitate a revision of the format. This is especially important when tight schedules are encountered.

Reference to the BMI outline, the SRI outline, and Regulatory Guides 3.26 and 3.39 will be necessary for an in-depth understanding of the following comments :

\section{CHAPTER 1.0 Introduction and General Description of the Plant}

a. Under subchapter 1.2 "General Plant Description," it would be helpful to the overall understanding of the proposed plant to provide a drawing of the overall facility plan. This could be a drawing developed for Chapter 5.1.

It should be noted that the NRC's review practice on nuclear power plants has been to split the SAR subchapters into groups for review by their specialists. Chapters that describe the overall plant in summary form and contain general arrangement drawings are included in all groups so that sufficient background information is available for the specialists to perform their review without constant reference to the entire SAR. Chapter 1 contains this type of general information.

b. Subchapter 1.5 - "Requirements for Further Technical Information" should be included for items such as long term monitoring techniques if required. Since BMI provided an abridged content description for this chapter, reference to Regulatory Guide 3.26, Chapter 1, will provide expanded guidance on the type and nature of the descriptions desired.

c. The FSAR should include subchapter 1.6 - "Comparison of Fina1 and Preliminary Information" for completeness and to speed the licensing review process.

\section{CHAPTER 2.0 Summary Safety Analysis}

a. Since BMI provided an abridged content description, more specific guidance as to the content for this chapter can be obtained by reference to Chapter 2 of either Regulatory Guide 3.26, as recommended by SRI, or Regulatory Guide 3.39.

b. It is suggested that BMI subchapter 2.5 "Release of Radioactive Materials During Passive Period" be re-structured into a subheading of "Accidents" subchapter 2.4 in order to maintain format consistency with the structure of Chapter 9 "Accident Safety Analysis."

\section{CHAPTER 3.0 Stte Characteristic}

a. Since BMI only provided an outline, it is suggested that Chapter 3 from either Division 3 SAR format guides 3.26 or 3.39 be used in order to provide more description of the information required by NRC for their review.

b. From the site description viewpoint, it may he useful to conoidcr the waste repository facility as consisting of two parts, a waste processing and 
emplacement facility and a storage medium. Although parts of the repository belong to both parts of the system, by and large the former has a working IIfe of a few tens of years and can be engineered to ameliorate existing conditions whereas the latter has a working 11 fe of hundreds of thousands of years and cannot readily be modifled or improved during its required lifetime. Because of this unlque situation, the confinement capabilities of the underground facllities are essentially those of the site. It follows that Chapter 3 is of critical importance and that the site description process must be one which provides all data required for both the short-term and long-term stability evaluations. Chapter 3 then becomes, in a sense, a defense of the site selection process, and the descriptions of site characteristics set down in Chapter 3 must demonstrate that the waste storage medium should remain stable and unbreached throughout the life of the facility.

c. The SRI outline provides additional guidance specifically for a waste repository facility. In particular subchapter 3.1 .5 and 3.1 .6 (geography and demography) and 3.3.5 and 3.3.6 (meteorology) entries should be worked into the SAR format guide. In addition, the geological and hydrological information provided In SRI subchapters 8.1 through 8.5 which deals with the projected long-term behavior of the undisturbed site should be integrated into this section.

d. The following specific comments address the SRI outline and are offered in order to partially extend either Regulatory Gulde 3.26 or 3.39 to include topics unique to a waste repository facility safety analysis.

(1) Subchapter 3.3.5.1 - Ple1stocene C11mate

Some of the material here (proximity to continental and alpine glaciers, occurrence of periglacial features, and Pleistocene erostonal features, etc.) is more properly in the scope of geological studies. Th1s material should be incorporated into the regional geology subchapter $(3.6 .1 .1)$ and cross-referenced.

(2) Subchapter 3.4.12 (addition) - Effects of C1imate Changes

Discuss the effects of substantial changes in climate such as an fee age, on the putential for flooding the sealed repository. Examine scenarios of changes in stream base levels due to changes in sea levels, draining or daming of lakes, etc., and the effects of those changes on the rate of downcutting and on the potential for exposure of the strata containing the repository.

(3) Subchapter 3.5.1.6 (addition) - Potential Long-Term Changes

Discuss the ways in which the ground water flow regime would probably change if a major shift in ground levels such as would be expected from radical alteration in climate, base levels, etc. were to occur. How would these changes affect the formation in which the waste is deposited?

(4) Subchapter 3.6.1.1 - Regional Geology

Item 4. Discuss the regional geological and structural history (this is clearer and more specific) to evaluate the suitability 
of the region to accommodate a waste repository. Provide detailed regional gravity and magnetic maps, isopach maps of the principal geologic units, structure and fault maps, a map showing areas of mineral and fluid extraction, and stratigraphic sections, as well as supporting data such as remote sensing imagery, boring logs, etc.

Item 8. Add here the material from 3.3.5.1 as discussed above.

Item 9. Provide a detailed description of the chemistry, mineralogy, and fluids contained in rocks in, above and below the repository. Compare these parameters with those of average sedimentary rocks to ensure that no unusual concentrations exist which may cause the repository to become a target for mineral exploration in the distant future.

(5) Subchapter 3.6.1.2 Site Geology - Surface

Item 3. Add after the first sentence "Relate these site structura1 features to regional tectonics and regional structural features."

(6). Subchapter 3.6.1.3 Site Geology - Subsurface

Item 5. This material belongs in 4.3.12, since it is more closely related to mine safety than to geological characteristics of the site.

(7) Subchapter 3.6.4.2 Properties of Underlying Mater Lals

Add to 1ist of properties required the following: "sensitivity, swelling, ion exchange, overconsolidation ratio, and mineralogy."

(8) Subchapter 3.8 Summary of Conditions Affecting Facility Construction and Operating Requirements

Add final sentence "Include pertinent facts developed in either Subchapter 5.4 or 6.1 .4 on potential and actual reactions between the waste and the storage medium."

\section{CHAPTER 4.0 Princ1pal Des1gn Criterla}

a. In BMI subchapter 4.4.5 "Quality Assurance Classification," we suggest the use of some classification other than Class 1, 2 and 3 in order to avoid any possible confusion with ASME Boiler and Pressure Vessel Code, Section III, classification, as utilized in nuclear power plant components, unless code class components are required for safe operation.

b. SRI subchapter 4.2.4 "Groundwater Design Considerations" would help expand BMI 4.2.3.5 "Subsurface Aquifers."

c. SRI subchapters 4.2.6 "Mined Materia1," 4.3.7 "Thermal Impact," 4.3.12 "Mine Safety Construction Criterla" and 4.5 "Engineered Retrievability" should be worked into this chapter's outline. These are unique criteria, pertinent to the waste repository facility.

d. SRI subchapter 4.6 "Decommissioning" should be substituted for BMI's 4.5 as it presents a more structured format guide. 


\section{CHAPTER 5.0 Facility Design}

a. Chapter 5 of the BMI outline was difficult to follow. On detailed examination it became apparent that the outline was overly concept specific and that the outline structure contained too much repetition. Some of the format difficulties may have been introduced by force fitting to Regulatory Guide 3.26 format (Fue1 Reprocessing plants). It should be noted that both Regulatory Guides 3.26 and 3.39 are geared to basically chemical processes and that the format structure of the facilities description chapter also reflects this process orientation, however, not nearly as much as Chapter 6 "Process Systems." Since the waste repository processes are predominantly remote and contact materials handling operations, both of which are physical operations, the SAR format guide for Uranium Enrichment Facilities, Regulatory Guide 3.25, would seem to be more appropriate for Chapters 5 and 6 .

b. With the preceding comments in mind, it is suggested that Chapter 5 include only facility descriptions and Chapter 6 include process system descriptions.

Table 2 presents a recommended outline for Chapter 5 which sequentially. addresses the above ground facilities, shafts, and below ground facllities. This format lends itself to the decommissloning sequence of removing above grade facilities, sealing of shafts and then the long term isolation of below grade areas with possible surveillance. Table 2 also cross-references the appropriate subchapter entries of both the SRI outline and BMI outline. The left hand side of the table Indicates Regulatory Guide 3.25 outline for reference only.

c. BMI's subchapter 5.6.2 "Mined Materials Handling Systems" has been included in Chapter 6 under the subchapter "Other Processing Systems," 6.3 .11 .

\section{CHAPTER 6.0 Process Systems}

a. The BMI Chapter 6 was also difficult to follow, most likely for the same reasons as stated in the comments on Chapter 5. In particular the second decimal headings refer to facility areas and not to the process or its operation. In some instances, the lacility description and its design requirements are included here. For clarity to a reviewer and ease of SAR preparation, it is suggested that the facility be described completely in Chapter 5 and that Chapter 6 describe the sequence of handling each major type of waste, referencing back to Chapter 5 for the bullding and below grade layouts as necessary, tylng in the support service systems and their safety features, and cross-referencing operating procedures contained in Chapter 10.

b. Table 3 completes the separation of facilities from systems as initiated in Chapter 5 review comments. This table presents a recommended outline substitute for Chapter 6 and contains similar information as portrayed in Table 2 .

c. Within the framework of the proposed SAR format outlines, as within the Division 3 Regulatory Guides, subchapters 5.2 "Above Ground Facilities," 5.3 "Shafts" and 5.4 "Below Ground Fac1lities" together with subchapter 6.1.4 "Identification of Items for Safety Analysis Concern" should satisfactorily bridge the gap between subchapter 3.7 "Summary of Conditions Affecting Facility Construction and Operating Requirements" and Chapter 9 "Accident Safety Analysis" 
TABLE 2

RECOMMENDED OUTLINE FOR SAR CHAPTER 5

REGULATORY GUIDE 3.25 OUTLINE

CHAPTER 5 FACILITY DES IGN

\subsection{Site Description}

5.1.1 Location and Facility Layout

5.1.2 Principal Features

\section{RECOMMENDED OUTLINE}

CHAPTER 5 FACILITY DESIGN

\section{I Summary Description}

5.1.1 Location and Facility Layout

5.1.2 Principal Features

5.1.2.1 Site. Bounciary

5.1.2.2 Exclusion Area

5.1.2.3 Restricted Area

5.1.2.4 Site Utility Supplies and Systems

5.1.2.5 Storage Facilities

5.1 .2 .6 Stacks

5.1.2.7 Rail Systems

5.1.2.8 Underground Facilities

5.2 Above Ground Facilities

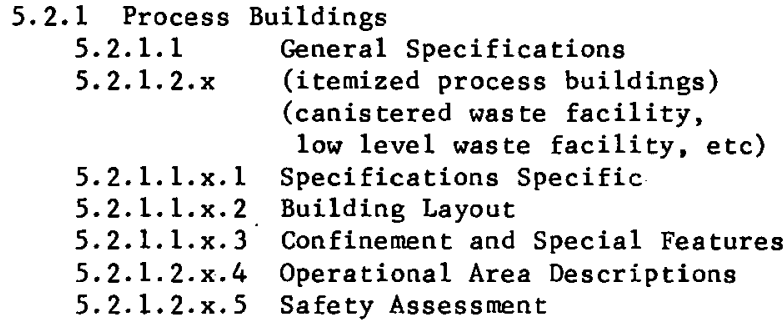

5.3 Auxiliary Buildings and Components

5.3.1 Structural Specifications 5.3.2 Builting Layout

5.4 Items Requiring Further Development

5.5 Changes from. the PSAR

\subsubsection{Support Buildings}

Similar outline as 5.2 .1 above

5.2.3 Support Areas

$$
\text { Similar outline as 5.2.1 above }
$$

5.3 Shafts (Similar Structure as 5.2.1 above)

5.4 Below Ground Facilities (Similar Structure as

$$
\text { 5.2.1 above) }
$$

5.5 Items Requiring Further Development

5.6 Changes from the PSAR (FSAR only)
PROPOSED OUTLINE SUBCHAPTERS

$\underline{B M I}$

$\underline{\text { SRI }}$

5.1

5.

5.1 .1

5.1 .2

5.1 .2 .1

5.1 .2 .2

5.1 .2 .3

5.1 .2 .4

5.1 .2 .6

5.1 .2 .7

5.1 .1

5.1 .2 .1

5.1 .2 .2

5.1 .2 .3
5.1 .2 .4

5.1 .2 .5

5.1 .2 .6

5.1 .2 .7

$5.2,5.3$

$5.2 .1,5.3 .1$

5.2 .1

$5.2 .2,5.3 .2$

5.2.2.1

$5.2 .3,5.2 .4,5.3 .3 \quad 5.2 .3$

5.2 .5

$5.3 .4,5.6 .1,5.6 .3$, $5.6 .4,5.6 .5,5.6 .6$

5.6 .2

5.4

5. 3

5.5

$5.3, \varepsilon .1$

through 8.5

5.8 


\section{REGULATORY GUIDE 3.25 OUTLINE}

CHAPTER 6 SYSEEMS AND COMPONENT DESIGY

\subsection{Genera 1}

6.1 .1 Requirements

6.1.2 Narrative Description

6.1.3 Flowsheets

6.1.4 Identification of Items for Safety Analysis Concern

6.2 Process Chemistry and Physical

\section{Principles}

6.3 Enrichment and Jther Processing Systems

6.3.1., 2, 3, etc. Process Identilication

6.3.x.1 Functional Description

6.3.X.2 Major Jomponents

6.3.X.3 Iesign Description

6.3.X.4 Safety Criteria and Assurance

6.3.X.5 Cperating Limits

6.3.X. 6 Component Spares

6.3.X.7 Instrumentation

6.4 Utility and Support Systems

6.4.1 Building Ventilation

6.4.2 Electrical

6.4.3 Compressed Air

6.4.4 Steam Supply and Distribution

6.4.5 Water Supply

6.4.6 Process Heat Exchange

6.4.7 Sewage Treatment

6.4.8 Communication and Alarms

6.4.9 Fire Protection

\subsection{Sampling and Analyses}

6.6 Items Requiring Further Development

6.7 Changes from the PSAR

\section{RECOMMENDED OUTLINE}

CHAPTER 6 PROCESS SYSTEMS

\subsection{General}

6.1.1 Requirements

6.1.2 Narrative Description

6.1.3 Flowsheets

6.1.4 Identification of Items for Safety Analysis Concern

6.2 Mechanical Process Systems for Each of the

following, describe the waste handling

sequence including: Receiving, Storage,

Transfer, Inspection through Isolation

(Burial in Salt) (refer to flow sheets)

\subsubsection{Canistered Waste High Level,}

Cladding \& Intermediate Waste 6.2

6.2 .2 Low

(For each handling sequency include:)

6.2.1, 2, 3, etc. Process Identification

6.2.X.1 Function Description

6.2.X. 2 Ma jor Components

6.2.X.3 Design Description

6.2. 4 Safety Criteria and Assurance

6.2.X.5 Operating Iimits

6.2.X.6 Component Spares

6.2.X.7 Instrumentation

6.2.X.8 Retrieval Process

6.2.3 Mining Operations

6.3 Utility and Support Systems

6.3.1 Building Ventilation

6.3.2 Electrical

6.3.3 Compressed Air

6.3.4 Steam Supply and Distribution

6.3.5 Water Supply

6.3.6 Process Heat Exchange

6.3.7 Sewage Treatment

6.3.8 Communications and Alarms

6.3.9 Fire Protection

6.3.10 Maintenance

6.3.11 Others

6.4 Control Room (areas)

6.5 Sampling and Analyses

$5.7 .1,5.7 .2,5.7 .3$

5.7 .5

5.7 .6

5.7 .7

5.7 .8

5.7 .9

5.7 .11

5.7 .10

5.7 .13

$5.7 .12,5.7 .14,5.7 .15,5.6 .2$

6.9

5.5

5.5 .1

5.5 .2

5.5 .3

5.5 .4

5.5 .5

5.5 .7

5.5 .8

5.5 .9

5. 5.10

6. 6 Items Requiring Further Development

6.5

6.10

6.6

6.7 Changes from the PSAR (FSAR only)
6.1 .1

$\begin{array}{ll}.1 .2 & \\ .1 .3 & 8.1\end{array}$

rough 8.5

$2,6.7$ 
so as to demonstrate the suitability of the site for long-term storage of hazardous materials as well as for the relatively short-term operations phase. Subchapter 6.1 .4 should discuss how the thermal, radiological, and chemical properties of the buried wastes may modify the characteristics of the surrounding medium, and how long-term confinement may be effected by these modifications.

\section{CHAPTER 7.0 Management of On-S1te Wastes}

a. Care should be exercised throughout SAR preparation to distinguish between on-site generated wastes, those wastes collected as a result of the repository facility operation, and the "waste" shipped into the facility for isolation (burial in the mine).

b. Suggest using the format and content of Regulatory cuide 3.26 Chapter 7 with the chapter title modified to read "Management of On-site Generated Wastes." In addition to being a format that is familiar to the NRC, Regulatory Cuide 3.26 content gives more definitive guidance. In an alternate strategy, which downplays the importance of on-site generated wastes, the description of the re radioactive waste treatment systems could be incorporated into the process descriptions of Chapter 6 .

CHAPTER 8.0 Radiation Protection

a. Subchapters should be included to address "Items Requiring Further Development" and "Changes from the PSAR" in order to complete this chapter to conform to existing Division 3 SAR formats.

b. Since the primary long-term protection against radiation release is the geologic storage medium, it is appropriate to discuss the potential

for radioactivity releases resulting from long-term geological and hydrological processes such as changes in ground water flows, faulting, fracture propagation, and renewed diapirism. Material contained in Chapter 3, which is required for these evaluations, should be cross-referenced. In addition, the environmenta 1 dosimetry models utilized in the radiological assessment should be either described, appended or referenced in this chapter.

\section{CHAPTER 9.0 Accident Safety Analysis}

a. Consideration should be given to subdividing the abnormal operations and accidents discussed in BMI subchapters 9.1 and 9.2 as occurring in surface, shaft and underground areas and analyzing each separately. This split may provide an accident grouping that is easier to follow and analyze, and would be consistent with the recommended separation of site characteristics commented on in Chapter 3 and the recommended format for Chapter 5, "Facilities Design."

b. SRI subchapters 7.3 .1 and 7.3 .2 provide additional guidance for the development of BMI subchapters 9.1 and 9.2 .

c. The material contained in SRI Chapter 8 provides a good start on accident scenarios for the long-term passive phase. These accident scenarios should be further developed and cross-referenced with the site description of Chapter 3 .

10. CHAPTER 10.0 Conduct of Operations

a. Operations may have to include long-term surveillance after decomissioning. 
b. A separate document covering physical security will most likely be required and should be referenced in this chapter.

c. The operations oriented portions of BMI subchapter 6.5 "Mining Operations," SRI subchapters 5.6 "Environmental Safety Design" and 5.7 "Mine Enforcement and Safety Administration" should be restructured and included in this chapter.

d. SRI subchapter 5.6 "Environmental Safety Design" provides additional input items for this chapter.

11. CHAPTER 11.0 Technica1 Specifications

a. The SRI Chapter 10 should be substituted for BMI Chapter 11 since it contains a more detailed breakdown of the required information. The BMI Chapter 11 provided only an outline.

b. It is suggested that consideration be given to changing this chapter title to "Operating Controls and Limits," as presented in Regulatory Guide 3.39 , to differentiate this facility from a nuclear power plant licensed under 10CFR50.

c. For more definitive description of the information required in this chapter refer to Regulatory Guide 3.6 "Content of Technical Specifications for Fuel Reprocessing Plants," April, 1973.

\section{CHAPTER 12.0 Quality Assurance}

a. Since BMI provided an outline on1y, suggest the substitution for use and guidance of Chapter 12 "Quality Assurance' from Regulatory Guide 3.39, "Standard Format and Content of License Applications for Plutonium Processing and Fuel Fabrication Plants." This is the latest and most complete Division 3 Regulatory Guide and reflects current NRC requirements.

b. It might be desirable to add a subchapter covering any Quality Assurance envisioned for the post operation phase such as long-term surveillance if utilized.

c. Attention should be given to Quality Assurance plans for mine sealing and surface decommissioning. 


\section{SAR SCHEDULE GUIDANCE}

SAR scheduling can be viewed from two aspects. The SAR development activities can be considered as fragnets (logic sequence inputs) to the overall project schedule or, at the other extreme, the SAR, from planning input stage to delivery of the final bound copy, can be treated as a total schedule in itself. Both viewpoints must be examined and subsequently meshed in order to develop a consistent overall project schedule. The approach utilized in this study was to maintain the overall project schedule as a fixed constraint and develop a realistic detailed PSAR schedule within the given framework; this approach is based mainly upon the document development philosophy utilized for many nuclear power plant projects. In addition, it has been assumed that the SAR document activity for the waste repository facility is not on the critical path so that maximum SAR manday efficiency can be achieved. This implies that a substantial change in the duration of any SAR preparation activity will not significantly affect the overall project schedule. If this is not the case, alternate schedules can be developed that contain greater use of parallel activities to shorten the SAR draft preparation time duration at the added expense of both additional manpower and mandays.

A portion of the overa 11 project schedule covering the SAR activities and their major interfacing activities is shown on Figure 1, Overa11 SAR Schedule. The key start and stop dates were obtained from OWI and are listed in Table 4. In the event of substantial change in any of the 1 isted key dates, a review of the SAR schedule impact should be performed to uncover potential inconsistencies and gain advance warning of any resulting project schedule slippage.

In order to maximize the SAR preparation guidance, the detailed SAR schedule has been limited to the PSAR stage. This selection was based on the judgment that more and varied difficulties will be encountered in the PSAR preparation than in FSAR preparation, and $1 t$ is quite evident that there is considerably less lead time for PSAR preparation than for FSAR preparation. In addition, the FSAR offers the alternative development approach of a continual, low level of effort, updating of the PSAR as a means of compiling the SAR document, whereas the PSAR requires a major, relatively short term, effort.

The chapter by chapter PSAR development scherile shown on Figure 2 is based upon the reference format developed in Section IV and includes the interfacing activities of engineering, site related activities and supporting studies. The logic behind the sequential preparation of the PSAR chapters has been briefly summarized in a matrix on Figure 3 and indicates the prerequisite SAR chapter content knowledge require'. for a consistent, complete PSAR document. Alternate development schedules and sequence matrices can be prepared in a similar manner for other assumed format structures.

The following is a short description of the main features inherent in the PSAR development schedule presented in Figure 2. A key controlling activity should be understood to mean a section of a chapter of the SAR which requires major effort and controls the time for completion of the chapter.

Once the site investigations have progressed sufficiently and studies of accident scenarios for isolated waste in geological formations have been cumpleted, dratt preparation of Chepters 3, 4 y ind 9 should be started. 


\section{FIGURE 1}

OVERALL SAR SCHEDULE

CALENDAR YEAR

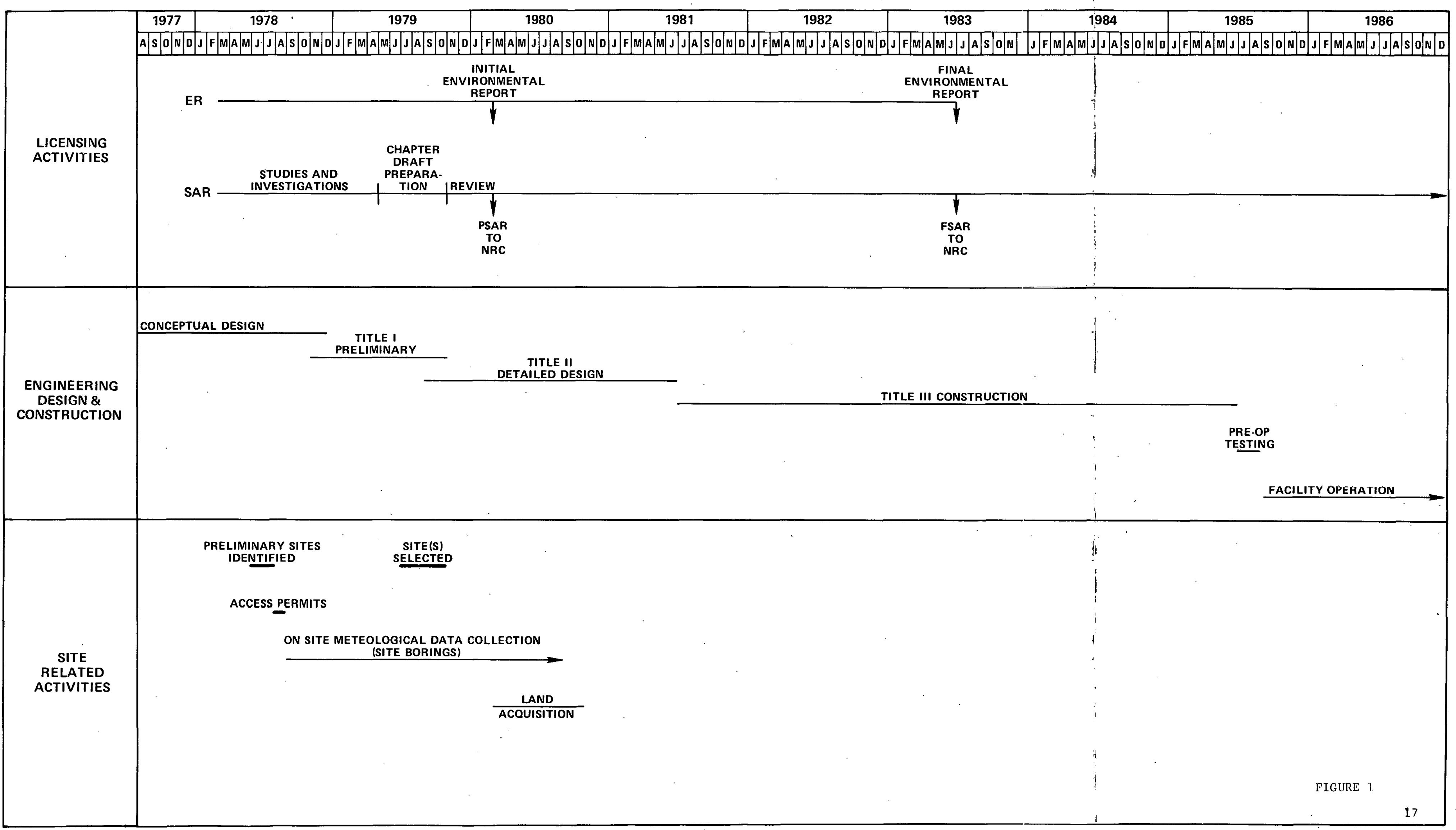


TABLE 4

WASTE REPOSITORY FACILITY

TENTATIVE LICENSING SCHEDULE

INPUT

CALENDAR DATES

START COMPLETE

1. $\underline{\text { SITE }}$
a) Preliminary Locations (30 sq mi)
$5 / 78 *$
$.7 / 78+$
b) Selected site (s)
$7 / 79 *$
$11 / 79 \dagger$
c) Land Acquisition
$3 / 80$
$10 / 80$
d) On site meterological station
$8 / 78$

2. ENGINEERING
a) Conceptua 1
b) Title I
c) Title II
d) Title III (Construction)
e) Pre-operation testing

$4 / 77$

$12 / 78$

$10 / 78$

$10 / 79$

$7 / 81$

$7 / 81$

$7 / 85$

$7 / 85$

$9 / 85$

3. FACILITY OPERATION

$9 / 85$

4. LICENSING
a) PSAR
$3 / 78$
$2 / 80$
b) FSAR
$2 / 80$
$6 / 83$
c) Initial Environmental Report
$3 / 78$
$2 / 80$
d) Final Environmental Report
$2 / 80$
$6 / 83$
Access Permits
$7 / 78$
$8 / 78$
PDEIS $\ddagger$
to ERDA
$9 / 79$

* Selection by OWI

$\uparrow$ Approved by ERD $\Lambda$

† Preliminary Draft

Environmental Impact Statement 
FIGURE 2

PSAR DEVELOPMENT SCHEDULE

CALENDAR YEAR

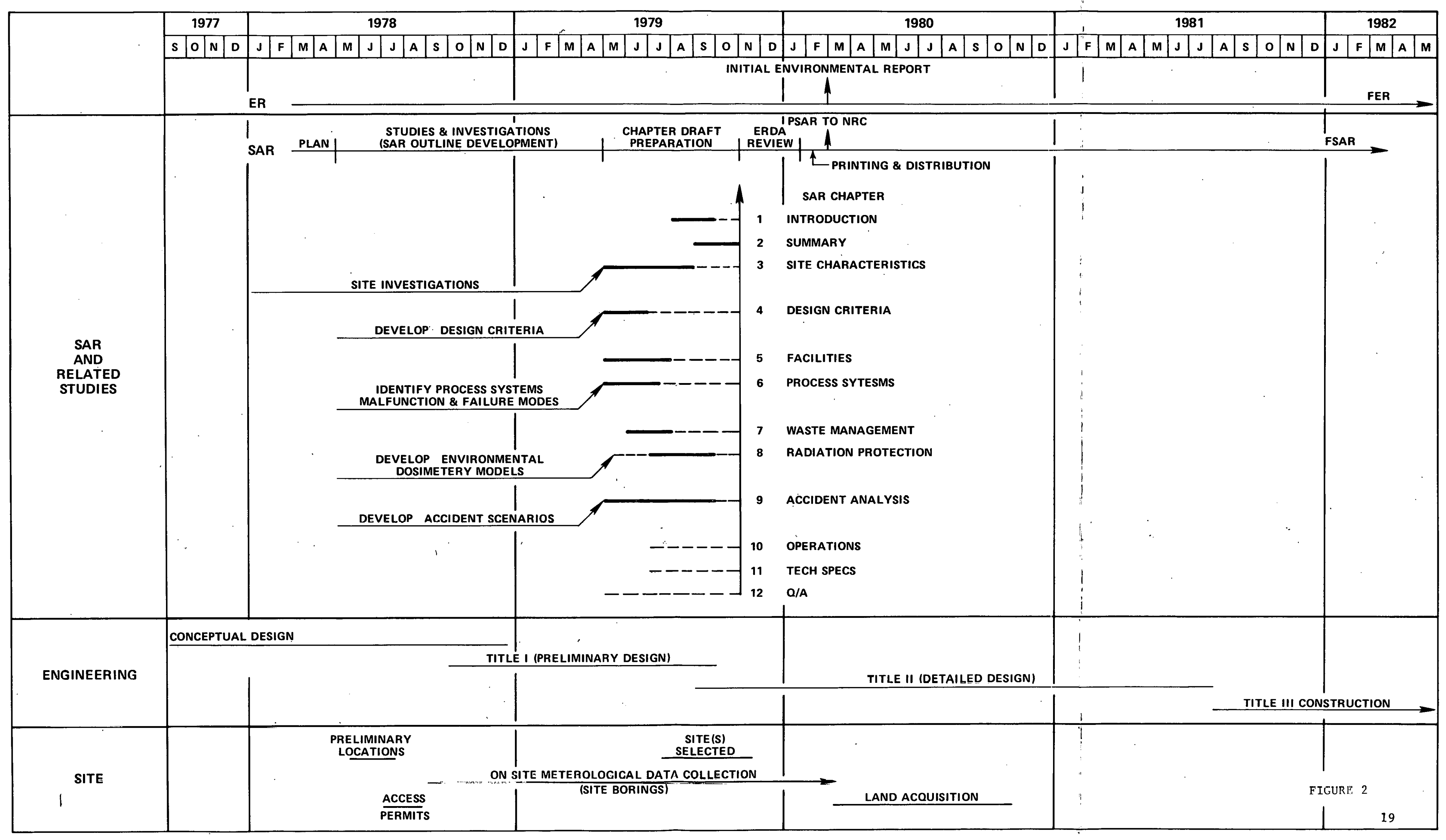


SAR CHAPTER PREPARATION SEQUENCE LOGIC

SAR CHAPTER

1.0 INTRODUCTION AND GENERAL DESCRIPTION OF THE PLANT

2.0 SUMMARY SAFETY ANALYSIS

3.0 SITE CHARACTERISTICS

4.0 PRINCIPAL DESIGN CRITERIA

5.0 FACILITY DESIGN

6.0 PROCESS SYSTEMS

7.0 WASTE CONFINEMENT AND MANAGEMENT

8.0 RADIATION PROTECTION

9.0 ACCIDENT SAFETY ANALYSIS

10.0 CONDUCT OF OPERATIONS

11.0 TECHNICAL SPECIFICATIONS

12.0 QUALITY ASSURANCE

$X$ - Draft preparation prerequisite

0 - Feedback for draft checking
INTERFACING CHAPTER INPUTS

$\begin{array}{lllllll}3 & 4 & 5 & 6 & 7 & 8 & 9\end{array}$

$\mathrm{X} \quad \mathrm{X}$

X $\quad \mathrm{X} \quad \mathrm{X}$ X

000

0

X $\mathrm{X}$ X

$\begin{array}{lll}0 & \mathrm{X} & 0\end{array}$

$\begin{array}{llll} & \mathrm{X} & & \mathrm{X} \\ \mathrm{X} & \mathrm{X} & \mathrm{X} & \mathrm{X} \\ \mathrm{X} & & \mathrm{X} & \mathrm{X} \\ & & & \mathrm{X} \\ & & & \mathrm{x}\end{array}$


Chapter 3 - This chapter is mostly site dependent. The key controliing activitles, which will also be required for quantitative a spects of Chapter 9, are subchapter 3.3 "Meteorology". and subchapter 3.7 on "Summary of Conditions Affecting Facility Construction."

Chapter 9 - Initial drafts will be based on the results of the study on accident scenarios, conceptual design features as modified by the latest input from Title 1 Engineering, and seismic design parameters from Chapter 3. Subsequent drafts of Chapter 9 will be required as detailed engineering proceeds, further site related information is developed, and the accident scenarios are refined.

Chapter 4 - This chapter should draw upon Chapters 3 and 9 and published regulatory guidelines in its initial stages. The criteria developed in Chapter 4 will be applied to the facility designs described in Chapter 5 and to the systems housed in these facilities in Chapter 6. The criteria developed in Section 4.3 should subsequently be cross-checked against Chapter 9 , Section 6.1 .4 and Section 3.7. The key controlling activity for Chapter 4 will be to develop and complle the design criteria for the mine, especially in the isolated waste storage areas.

Chapters 5 and 6 should be started as soon as possible after the initiation of Chapters 3,4 and 9 .

Chapter 6 - The key controlling activity for Chapter 6 is to identify the items of safety concern in Section 6.1.4. Chapter 6 requires data from Chapters 3,4 and 9 for its development and proceeds concurrently.

Chapter 5 - The key activities of Chapter 5 will be those that describe the structural foundation design of buildings, mine and mine shafts, and all underground facilities. A prerequisite to completing this chapter is the site borings as well as geological and seismic data from Chapter 3. Process system design features from Chapter 6 determine the design of above and below ground facilities described in this chapter. The codes and standards referenced in Chapters 5 and 6 are used to cross-check and up-date criteria of Chapter 4.

Chapters 7 and 8 require input from Chapters 3, 4, 5 and 6; therefore, they cannot be productively initiated until a rough draft copy of these prerequisite chapters have been prepared.

Chapter 7 - Th1s chapter presents the design basis and supporting analysis for demonstrating that all radioactive and non-radioactive waste materials generated on-site will be contained safely over the operational life of the waste isolation facility. This chapter may also provide guidelines for off-site disposa 1 of solid wastes and contaminated equipment should this method be selected. The key controlling activity is the identification of on-site generated wastes and for this determination the data of Chapter 6 is a prerequisite. Any credible accidents related 
to waste confinement and management are correlated with Chapter 9. The criteria used as design bases are crosschecked against radiation protection criteria contained in Chapter 8 and against overall criteria in Chapter 4.

Chapter 8 - The off-site dose assessment is the key controlling activity in Chapter 8 , and the development of this chapter requires input from Chapters $3,5,6,7$ and 9 as well as a working environmental dosimetry model.

Chapters 10,11 and 12 have a minimum of interfacing and can be utilized to smooth out the manpower loading during SAR draft preparation.

Chapter 10 - This chapter requires a consideration of appropriate regulatory requirements and input from Chapter 6 . This chapter can be considered to be a low level of effort activity to be developed during slack periods and as such, should not have any appreciable impact on the overall schedule.

Chapter 11 - This chapter on technical specifications can also be considered as a low level effort activity requiring input mainly from Chapter 6. Development of this chapter should not impact significantly on the overall schedule.

Chapter 12 - This chapter is essentially independent of the other SAR chapters and takes its guidance mainly from published regulations and past experience of the licensee.

Chapters 1 and 2 are summary in content so that their late start is necessary.

Chapter 1 - This chapter is a general description of the key features of the plant. As the schedule shows, the writing of this chapter should begin when the first drafts of all other chapters of the PSAR are either completed or are over 70 percent complete. Subchapter 1.5 items requiring further technical information will most 1 ikely require input from Chapters 5 and 6 .

Chapter 2 - The last scheduled chapter summarizes al1 aspects which relate to providing safety for the protection of operating personnel and the public during the active operating period and the extended passive period. The radiological impact of norma1 and abnormal operations is the key activity and requires input mainly from Chapters 3,5 , 6,8 and 9 .

The following observations are offered for guidance as a result of a review of the PSAR schedule.

1. Due to the late selection of the intended site, parallel efforts in site data collection at several sites may be required. This will then require a substantially larger data reduction program leading to either a number of drafts of Chapter 3 corresponding to the various candidate sites or the generation of a combined, enveloping, Chapter 3 (Site Characteristics). In either case the work load would be greater than normal1y encountered in nuclear power plant SAR development and the risk may include a Chapter 5, "Facility Design" incompatible witli the selected oftco. 
2. The overlapping of Title 1 Englneering (Preliminary Design) and the PSAR chapter development will require close integration in order for the SAR to reflect the current status of design. Advance contact with the Title 1 engineer will be necessary so that good quality general arrangement drawings will be avallable for inclusion in Chapter 5.

3. With the overlapping of the design, site selection and PSAR preparation, it is almost certain that. PSAR Amendments will be required and, consequently, should be planned for.

4. The development of accident scenarios must be based on conceptual design. This will then require a constant information exchange between the accident studies group and the group developing Title 1 design to insure that all credible accidents are being included and additionally, that those already addressed are still valid for incorporation into the PSAR.

5. Prior experience on a first of a kind factilty SAR indicates that a chapter by chapter outline prepared and reviewed prior to the commencement of chapter draft preparation will help significantly in preparation efficiency, document continuity and chapter cross-referencing. This outline development activity is shown on Figure 2 in parallel with studies and investigations. 


\section{SUGGESTIONS FOR ADDITIONAL SAR SUPPORT EFFORTS}

It is recommended that the following efforts be undertaken within the time frames indicated in order to facilitate the timely completion of SAR preparation activities for the waste repository facility:

1. Initiate a study of accident scenarios for isolated wastes stored in deep geologic formations based upon the conceptual facility design. This study should mechanistically define the potential paths of waste release to the biosphere and thus serve as the basis for SAR Chapter 9 "Accident Safety Analysis." As the preliminary design is defined the study should be expanded to include fallure mode and malfunction events in order to complete abnormal and accident items which are to be addressed in Chapter 9. In addition, this study should provide the material needed to integrate SAR subchapter 3.7, "Summary of (Site) Conditions Affecting Facility Construction and Operating Requirements," subchapter 5.4 "Below Ground Facilities," subchapter 6.1.4, "Identification of Items for Safety Analysis Concern" (Process Systems), and the "Accident Safety Analysis" of Chapter 9.

The study of accident scenarios should provide a comprehensive analysis with a tabulation of malfunctions and accidents so that no unanticipated credible events are discovered at subsequent critical licensing stages. In addition, a review of the developed accident scenarios will indicate the degree of SAR format and content suitability by identifying areas where additional facility description, design analysis and/or engineered safety features are required. Based upon the review, final modifications could then be made to the proposed SAR format guide.

If not already in progress, this study should be started immediately and continue through the design phases up to PSAR submittal. Figure 2, PSAR Development Schedule, indicates that this activity. is a prerequisite to Chapter 9 draft preparation.

2. Review a11 10 divisions of the USNRC Regulatory Guides for possible applicability to the waste repnsitory facility. Identify those that have direct applicability and those that contain some degree of philosophy guidance for facility design, construction and/or operation. This activity will provide guidance to the designers and also assist in licensing defense activities by supplying a ready reference of existing NRC criteria.

To be of maximum benefit this task should be completed prior to the start of Title 1 Engineering and then reviewed again prior to PSAR submittal. 